\title{
OS ALUNOS DO PROEJA NO IFRN CAMPUS CURRAIS NOVOS COMO USUÁRIOS DO SERVIÇO DE EMPRÉSTIMO DA BIBLIOTECA
}

\author{
Iara Celly Gomes da Silva
}

Bibliotecária do IFRN, Campus Currais Novos. Aluna do curso de Especialização em Educação Profissional Integrada à Educação Básica na Modalidade Educação de Jovens e Adultos do IFRN, Campus Currais Novos. E-mail: iarasilva@cefetrn.br

Virna Lúcia Cunha de Farias

Docente do IFRN, Campus Currais Novos. Doutoranda em Literatura e Cultura pela

Universidade Federal da Paraíba - UFPB. E-mail: virna@cefetrn.br

\begin{abstract}
RESUMO
Analisa-se, neste trabalho, a utilização do serviço de empréstimo da Biblioteca pelos alunos do PROEJA no IFRN Campus Currais Novos. Apresenta breve histórico do ensino na modalidade EJA no Instituto quando este ainda era o CEFET/RN, listando os cursos oferecidos atualmente no Campus Currais Novos. Aborda o estudo de usuários de bibliotecas, enfatizando o uso do serviço de empréstimo, relatando os empréstimos efetuados aos alunos do PROEJA do turno noturno e relacionando os assuntos dos livros que são emprestados, através de registros de cadastro e empréstimo de materiais nas fichas dos alunos. Os resultados apontam que os alunos do PROEJA utilizam pouco o serviço de empréstimo da Biblioteca e que pegam emprestados mais os livros obrigatórios requeridos pelas disciplinas. Constata-se que ações devem ser efetivadas para estimular o uso desse serviço pelos sujeitos da pesquisa.
\end{abstract}

PALAVRAS-CHAVE: Serviço de empréstimo, Usuários de bibliotecas, Educação de Jovens e Adultos.

\section{LOS ALUMNOS DEL PROEJA EN IFRN CAMPUS CURRAIS NOVOS COMO USUARIOS DEL SERVICIO DE PRÉSTAMO DE LA BIBLIOTECA}

\section{RESUMEN}

En este trabajo, se analiza, el uso del servicio de préstamo de la Biblioteca por los alumnos del PROEJA en IFRN Campus Currais Novos. Presenta breve histórico de la enseñanza en la modalidad EJA en el Instituto, cuando este todavía era CEFET/RN, enumerando los cursos ofrecidos actualmente en el Campus Currais Novos. Aborda el estudio de usuarios de biblioteca, subrayando el uso de los servicios de préstamo, relatando los préstamos efectuados a los alumnos del PROEJA del turno nocturno y relacionando a los contenidos de los libros que son prestados, a través de registros de catastro y préstamo de materiales en las fichas de los alumnos. Los resultados señalan que los alumnos de PROEJA utilizan poco el servicio de préstamo de la Biblioteca y que cogen prestado más los libros obligatorios demandados por las asignaturas. Constata que acciones deben ser efectuadas para estimular el uso de este servicio por los sujetos de la encuesta.

PALABRAS LLAVES: Servicio de préstamo, Usuarios de bibliotecas, Educación de Jóvenes y Adultos. 


\section{OS ALUNOS DO PROEJA NO IFRN CAMPUS CURRAIS NOVOS COMO USUÁRIOS DO SERVIÇO DE EMPRÉSTIMO DA BIBLIOTECA}

\section{INTRODUÇÃO}

A Educação de Jovens e Adultos (EJA) no Brasil é constituída de particularidades que ultrapassam a concepção estrita de escolarização, pois permeiam intenções de qualificação profissional, formação cultural e cidadã, envolvendo espaços que vão além do ambiente da escola (DI PIERRO; JÓIA; RIBEIRO, 2001). Sob esse ângulo de análise, torna-se evidente que a EJA abarca questões e problemas relacionados também às difíceis condições sociais e econômicas do país, que acarretam em todas as implicações que podem decorrer da falta de escolarização de indivíduos na idade própria em que deveriam ingressar (e permanecer com sucesso) no sistema escolar brasileiro.

De acordo com o Documento Base de concepções e princípios do Programa de Integração da Educação Profissional com a Educação Básica na Modalidade de Educação de Jovens e Adultos (PROEJA), a EJA no contexto nacional é caracterizada por fatores como: descontinuidade de ações já tão escassas e isoladas, restrições de financiamento para o bom desenvolvimento de programas, existência de marcante número de jovens provenientes, sobretudo, do ensino fundamental regular sem êxito. Percebe-se, assim, que a EJA envolve principalmente cidadãos periféricos e que também foi crescente a demanda social por um programa específico para essa modalidade (BRASIL, 2007). Desse modo, a partir de discussões em torno da universalização da educação básica de jovens e adultos em associação à formação para o trabalho, houve a promulgação do decreto 5.478/2005, substituído posteriormente pelo decreto 5.840/2006, que deu origem a atual implantação do PROEJA.

O Programa inclui a perspectiva de uma formação cidadã, educacional e laboral. Assim, ele nasce tencionando-se a "formação na vida e para a vida e não apenas de qualificação do mercado ou para ele” (BRASIL, 2007, p.13).

Conforme a Secretaria de Educação Profissional e Tecnológica (SETEC), os cursos oferecidos pelo PROEJA são:

1- Educação profissional técnica de nível médio com ensino médio, destinado a quem já concluiu o ensino fundamental e ainda não possui o ensino médio e pretende adquirir o título de técnico.

2- Formação inicial e continuada com o ensino médio, destinado a quem já concluiu o ensino fundamental e ainda não possui o ensino médio e pretende adquirir uma formação profissional mais rápida.

3-Formação inicial e continuada com ensino fundamental ( $5^{\mathrm{a}}$ a $8^{\mathrm{a}}$ série ou $6^{\circ}$ a $9^{\circ}$ ano), para aqueles que já concluíram a primeira fase do ensino fundamental. Dependendo da necessidade regional de formação profissional, são, também, admitidos cursos de formação inicial e continuada com o ensino médio (BRASIL, 2009). 
Segundo o Decreto $n^{\circ} 5.840 / 2006$, tais cursos poderão ser oferecidos por instituições públicas de ensino federal, estaduais e municipais, entidades privadas nacionais de serviço social, aprendizagem e formação profissional vinculadas ao sistema sindical e entidades pertencentes ao “sistema S"1 (BRASIL, 2007, p.58).

No Rio Grande do Norte, o então Centro Federal de Educação Tecnológica (CEFET) passou a implantar cursos do PROEJA a partir do semestre 2006.2, nas Unidades de Ensino Descentralizadas (UNEDs) de Mossoró, Zona Norte de Natal, Currais Novos e Ipanguaçu, sendo que, à exceção da unidade de Mossoró que contava com 10 anos de funcionamento, as demais unidades já iniciaram suas atividades incluindo os cursos vinculados a esse Programa (MOURA, 2009).

Em decorrência da lei n. ${ }^{\circ}$ 11.892, de 29/12/2008, o CEFET-RN se transformou em Instituto Federal de Educação, Ciência e Tecnologia do Rio Grande do Norte (IFRN) e, com a reestruturação a partir do ano de 2009, as antigas UNEDs passaram ao status de Campi. (IFRN, 2009). A nova configuração do Instituto possibilita a ampliação da sua atuação educacional, impulsionando a formação de professores através dos cursos de licenciatura e permitindo a oferta de cursos de bacharelado, engenharia e pós-graduação stricto sensu (mestrado e doutorado) e lato sensu (aperfeiçoamento e especialização).

Atualmente, os cursos ofertados pelo Campus de Currais Novos são:

a) Curso Técnico de Nível Médio Subseqüente em Alimentos;

b) Curso Técnico de Nível Médio Subseqüente em Sistemas de Informação;

c) Curso Técnico de Nível Médio Integrado em Informática (inclusive na modalidade de EJA)

d) Curso Técnico de Nível Médio Integrado em Alimentos (inclusive na modalidade de EJA)

O objetivo geral dessa pesquisa é analisar o uso dos serviços da biblioteca pelos alunos matriculados nos cursos PROEJA do Campus Currais Novos do IFRN. Especificamente, tenciona-se identificar o perfil desses alunos quanto à utilização do serviço de empréstimo oferecido pela biblioteca para então sugerir ações para orientar esse tipo de público.

A EJA se constitui atualmente em um campo de estudo imprescindível no ambiente educacional das Instituições que ofertam essa modalidade de ensino. Pesquisas nessa área são fundamentais nesse momento, pois podem possibilitar um maior entendimento acerca das questões relacionadas a esse tema, tornando-o mais próximo da prática do dia a dia dessas escolas.

Conforme o Documento Base nacional preparatório à VI Conferência Internacional de Educação de Adultos (CONFINTEA), dados evidenciam que a oferta de EJA entre 1997 e 2006 apresenta uma evolução das matrículas, entretanto, as condições em que ocorre tal oferta apresentam deficiências de acordo com o censo escolar do Instituto Nacional de Estudos e Pesquisas Educacionais Anísio Teixeira (INEP), principalmente quanto à inexistência de bibliotecas e acesso ao computador na maior parte das instituições com

\footnotetext{
${ }^{1}$ Estão incluídas as organizações do Sistema "S": o Serviço Nacional de Aprendizagem Industrial (SENAI), Serviço Nacional de Aprendizagem Comercial (SENAC), Serviço Social da Indústria (SESI), Serviço Social do Comércio (SESC), Serviço Social do Transporte (SEST), Serviço Nacional de Aprendizagem Rural (SENAR) e Serviço Brasileiro de Apoio às Micro e Pequenas Empresas (SEBRAE). (BRASIL, 2007, p.58).
} 
matrículas em EJA. Os dados são alarmantes, especificamente nas escolas das regiões Norte e Nordeste do país e que se encontram na zona rural (BRASIL, 2008).

Com isso, percebe-se que ainda persiste uma grande quantidade da população com baixa escolaridade, apontando a necessidade de um sistema escolar no Brasil que melhore a qualidade do ensino em todas as modalidades, inclusive a EJA, com vistas à superação das desigualdades educacionais e sociais.

Deve-se entender que a EJA engloba um grupo heterogêneo, inserido em uma múltipla diversidade cultural: "mulheres, homens, crianças, adolescentes, jovens, adultos, idosos, pessoas com necessidades especiais, indígenas, afro-descendentes” (BRASIL, 2008, p.13), que devido a essa peculiaridade, possui demandas específicas de projetos políticopedagógicos e políticas públicas com a intenção de afirmar a igualdade de direitos de todos. Observa-se que a questão essencial é reverter a prática de que essa diversidade deve ser desencadeada em desigualdade.

O ambiente da Biblioteca pode favorecer a diminuição de disparidades e de exclusão, elevando o nível de informação, a igualdade no acesso e no uso desta, possibilitando uma melhor aprendizagem dos alunos. Conforme sinaliza a Federação Internacional de Associações de Bibliotecários e Bibliotecas: “as bibliotecas são o principal meio de acesso ao conhecimento, às idéias e à manifestação criativa, além de contribuir para o desenvolvimento e a manutenção da liberdade intelectual a que todos os cidadãos têm direito” (IFLA, 1999 apud BUENO, 2007).

A motivação para a presente pesquisa ocorreu pela necessidade de se compreender a utilização do serviço de empréstimo oferecido na biblioteca do IFRN Campus Currais Novos pelos alunos do PROEJA, visto que há carência de estudos que relacionem essas duas dimensões (biblioteca e público do PROEJA), já que o programa é relativamente recente, contando com apenas 2 anos e meio de implantação na referida Instituição de Ensino. A partir das constatações do estudo, pode-se delinear estratégias de intervenção que visem contribuir para a melhor utilização da biblioteca por esses usuários, ampliando suas potencialidades de desenvolvimento educacional.

Quanto à finalidade, o presente estudo enquadra-se como pesquisa descritiva que, em essência, se trata da interpretação de fatos observados/analisados, sem a interferência do pesquisador (RAMPAZZO, 2005, p. 53). Nesse caso, pretende-se analisar o uso do serviço de empréstimo da biblioteca aos alunos matriculados nos cursos PROEJA do Campus Currais Novos do IFRN. Desse modo, o universo da pesquisa foi composto pelos alunos matriculados nos cursos PROEJA oferecidos pelo Campus, ingressantes nos semestres 2008.2 e 2009.1 no turno noturno.

Para atingir tal objetivo, dividiu-se o trabalho em duas fases: inicialmente, foi realizada a pesquisa bibliográfica para se investigar trabalhos já realizados a respeito do perfil de alunos de PROEJA, bem como sobre o estudo de uso e usuários de bibliotecas. A contextualização teórica foi necessária para respaldar a pesquisa, que utilizou as rotinas (registros estatísticos) de cadastro de usuários e empréstimo de materiais como instrumentos para a coleta de dados, cujas análises se constituem no segundo momento do estudo. 


\section{PROEJA NO CAMPUS CURRAIS NOVOS DO IFRN}

A partir da aprovação do Plano de Desenvolvimento Institucional (PDI) do CEFET/RN 2005-2009, idealizou-se a Unidade de Ensino Descentralizada (UNED) de Currais Novos (CEFET-RN, 2008). A unidade foi inaugurada em 28 de junho de 2006, tendo suas atividades acadêmicas iniciadas em 25 de setembro de 2006, oferecendo cursos de nível técnico nas áreas profissionais de química (curso Técnico em Alimentos) e em Informática (curso Técnico em Sistemas de Informação).

Para iniciar as primeiras turmas, foram oferecidas 40 vagas para o Curso Técnico de Nível Médio Subseqüente em Alimentos (matutino), 30 vagas para o Curso Técnico de Nível Médio Subseqüente em Sistemas de Informação (vespertino) e 80 vagas para o Curso Técnico de Nível Médio Integrado em Alimentos na modalidade de EJA, sendo 40 vagas para o turno matutino e 40 vagas para o turno vespertino (CEFET-RN, 2008).

Em 2007, a unidade passou a contar com cerca de 350 alunos regularmente matriculados nos cursos técnicos nas modalidades integrada ao ensino médio (regular e PROEJA) e subseqüente (CEFET-RN, 2008).

Em 2008, o corpo discente foi ampliado para 522 alunos, além de ter ocorrido a $1^{\mathrm{a}}$ formatura na unidade no fim do primeiro semestre, quando 36 alunos concluíram os cursos Técnicos Subseqüentes em Alimentos e em Sistemas de Informação. A partir deste ano os cursos com novas turmas de PROEJA passaram a funcionar apenas no turno noturno, devido à grande evasão de alunos de turmas de PROEJA que funcionam nos turnos matutino e vespertino. Atualmente, existem 639 alunos matriculados no Campus do IFRN Currais Novos, sendo 117 alunos do $2^{\circ}$ período do Curso Técnico de Nível Médio Integrado em Alimentos na modalidade de EJA, do $2^{\circ}$ período do Curso Técnico de Nível Médio Integrado em Informática na modalidade de EJA e do $1^{\circ}$ período do curso Técnico em Informática na modalidade EJA do turno noturno.

\section{USUÁRIOS E BIBLIOTECA}

A biblioteca é o ambiente, por excelência, em que se encontra disponível uma variada gama de informações de toda natureza, principalmente informações que interessam à comunidade a qual a biblioteca atende. Nesse sentido, há a necessidade de se realizar estudos de usuários com a finalidade de atender cada vez mais às demandas dos clientes que freqüentam a biblioteca e utilizam seus serviços.

Estudos de usuários podem ser definidos como investigações que têm a finalidade de identificar quais as necessidades de informação dos indivíduos ou, ainda, para saber se tais necessidades por parte dos usuários de uma biblioteca ou centro de informação estão sendo satisfeitas de maneira adequada (FIGUEIREDO, 1979).

Os estudos sobre usuários da informação são importantes para o conhecimento do fluxo de informação científica e técnica, de sua demanda, da satisfação do usuário, dos resultados ou efeitos da informação sobre o conhecimento, do uso, aperfeiçoamento, relações e 
distribuição de recursos de sistemas de informação e tantos outros aspectos direta ou indiretamente relacionados à informação. Conseqüentemente, o âmbito dos estudos de usuários da informação não é bem delimitado e abrange desde os levantamentos de empréstimos em bibliotecas até pesquisas sobre o comportamento do usuário.

Os estudos de necessidades e usos de informação têm obedecido às mais diversas classificações do ponto de vista de vários autores, levando em conta diferentes fatores, componentes, metodologia etc. Lancaster (citado por PINHEIRO, 1982) classifica os estudos de usuários em dois tipos: os dirigidos a bibliotecas, isto é, investigações de como as bibliotecas e centros de informação são utilizados; e os dirigidos a usuários, que investigam como uma comunidade em particular obtém informações necessárias ao desenvolvimento de seu trabalho.

\section{USUÁRIOS E BIBLIOTECA DO CAMPUS CURRAIS NOVOS}

Durante o primeiro ano de funcionamento da então UNED Currais Novos, a biblioteca não contava com um profissional bibliotecário, visto que este somente foi contratado e iniciou suas atividades em setembro de 2007. A ausência de tal profissional trouxe prejuízos ao bom funcionamento desse setor, tais como: espaço físico inapropriado, controle de empréstimos inadequado, incorreta adoção das técnicas de catalogação, classificação e organização administrativa da biblioteca. A partir da presença do bibliotecário, a biblioteca passou por uma reestruturação: desde a adequação dos serviços e técnicas biblioteconômicas a até a mudança do espaço para uma sala maior devido a um atraso no término da construção do seu prédio definitivo.

Recentemente, enquanto aguarda a conclusão deste prédio, a biblioteca foi transferida para outra sala mais próxima da circulação dos alunos e com acesso à Internet, possibilitando o melhor desenvolvimento de serviços como: pesquisas acadêmicas para os usuários e consulta à interface web do Sistema de Automação de Bibliotecas - SIABI, já que esse sistema está em pleno funcionamento nos demais Campi do Instituto. Foi possível ainda melhorar o layout da biblioteca e incorporar estantes próprias para o acondicionamento de livros. Nesta sala existe somente uma mesa com cinco cadeiras para estudo, pois o espaço é insuficiente para disponibilizar uma quantidade maior.

Atualmente, a biblioteca conta com um acervo de 1.500 exemplares de livros, dentre os quais são didáticos (das disciplinas do Ensino Médio), técnicos (nas áreas de alimentos, informática) e da área de Educação. Possui ainda obras de referência (dicionários e enciclopédias), assinatura de um jornal diário, 300 fascículos de periódicos de assuntos gerais e um pequeno acervo de CDs-ROM e DVDs que ainda não estão disponíveis para o público, pois aguardam materiais específicos para seu tratamento técnico correto.

Com relação aos recursos humanos, conta com 1 bibliotecária, 1 servidor, com formação completa no Ensino Médio, além de 1 bolsista, aluna do Curso Técnico Integrado em Alimentos na Modalidade de EJA, 1 bolsista do Curso Técnico Integrado em Alimentos e 1 bolsista do Curso Técnico Integrado em Informática. O atendimento ao público funciona de segunda a sexta-feira, nos horários de $7 \mathrm{~h}$ às $11 \mathrm{~h}, 13 \mathrm{~h}$ às $17 \mathrm{~h}$ e $18 \mathrm{~h}$ às $22 \mathrm{~h}$. 
Os serviços oferecidos são: orientação bibliográfica e de pesquisa acadêmica na Internet, empréstimo/renovação/devolução e reserva de materiais. Estão habilitados a efetuar empréstimo de material: alunos, professores e servidores técnico-administrativos devidamente cadastrados na Biblioteca. Os alunos e servidores técnico-administrativos têm o direito de pegar por empréstimo até 3 livros pelo prazo de 7 dias; alunos concluintes ou de Especialização podem levar até 3 livros por 14 dias; e os professores, até 5 livros por 14 dias.

\section{USO DO SERVIÇO DE EMPRÉSTIMO PELOS ALUNOS PROEJA DO TURNO NOTURNO}

Para se ter um maior entendimento sobre os empréstimos realizados aos alunos do PROEJA no turno noturno, faz-se necessário primeiramente verificar a quantidade de alunos matriculados e, destes, quais estão cadastrados na Biblioteca.

Tabela 1: Quantidade de alunos PROEJA no turno noturno

\begin{tabular}{c|c|c|c|c}
\hline & ALIMENTOS & \multicolumn{2}{|c|}{ INFORMÁTICA } & TOTAL \\
\hline & $2^{\circ}$ período & $1^{\circ}$ Período & $2^{\circ}$ período & \\
\hline Matriculados & 39 & 42 & 36 & $\mathbf{1 1 7}$ \\
\hline Cadastrados na Biblioteca & 15 & 6 & 22 & $\mathbf{4 3}$ \\
\hline
\end{tabular}

Fonte: Dados da pesquisa (2009).

Conforme ilustra o quadro acima, constata-se que, dos 117 alunos do PROEJA matriculados no turno noturno do IFRN Campus Currais Novos, apenas 43 efetuaram seu cadastro na Biblioteca, quantidade que representa 36,75\% desses sujeitos. Essa baixa representatividade pode ser decorrente de vários fatores, dentre os quais, podem ser citados o desconhecimento da utilização dos serviços da Biblioteca e/ou desinteresse pela utilização de tais serviços.

Ressalta-se ainda que o quadro mais marcante se refere à disparidade entre os alunos do $1^{\circ}$ período de Informática matriculados e cadastrados na Biblioteca, pois somente 14,28\% desses sujeitos tiveram a iniciativa de se cadastrar.

É um dado que merece maior investigação, pois durante a primeira semana de aulas dessa turma foram realizadas atividades de integração aos diversos setores e serviços existentes no Campus e, dentre essas atividades, houve o momento de explanação da bibliotecária sobre a Biblioteca com relação às áreas de conhecimento contempladas no seu acervo, ao uso que os alunos poderiam fazer dos seus serviços, horário de funcionamento, direitos e deveres dos usuários etc. Entretanto, essas informações foram repassadas aos alunos em uma sala de aula, ou seja, eles não tiveram acesso às instalações físicas da Biblioteca, pois esta ainda está funcionando em um ambiente inadequado, com dimensões muito limitadas para receber uma turma com 42 alunos para uma visita orientada, em que eles poderiam se familiarizar com os livros e periódicos existentes nas estantes, conhecer na prática os 
serviços oferecidos, bem como o ambiente de estudo e o pessoal que trabalha na Biblioteca. Tais ações seriam facilitadoras para despertar o interesse desses alunos na utilização desse setor tão importante para o desenvolvimento educacional.

Com relação aos empréstimos realizados aos sujeitos da pesquisa no período de 02 de março a 13 de maio de 2009, contabilizou-se um total de 64 empréstimos, distribuídos de acordo com o quadro abaixo:

Tabela 2: Tipos de livros retirados por empréstimo no período de 02 de março a 13 de maio de 2009

\begin{tabular}{l|c|c|c|c}
\hline & ALIMENTOS & \multicolumn{2}{|c|}{ INFORMÁTICA } & \\
\cline { 2 - 5 } & $2^{\circ}$ período & $1^{\circ}$ período & $2^{\circ}$ período & TOTAL \\
\hline Didáticos & 28 & 0 & 6 & $\mathbf{3 4}$ \\
\hline Literários & 6 & 4 & 6 & $\mathbf{1 6}$ \\
\hline Técnicos / específicos & 5 & 0 & 4 & $\mathbf{9}$ \\
\hline Entretenimento & 5 & 0 & 0 & $\mathbf{5}$ \\
\hline EMPRÉSTIMOS POR TURMA & $\mathbf{4 4}$ & $\mathbf{4}$ & $\mathbf{1 6}$ & $\mathbf{6 4}$ \\
\hline
\end{tabular}

Fonte: Dados da pesquisa (2009).

Pode-se perceber que a maior parte dos empréstimos (68,75\%) foi realizada pelos alunos do $2^{\circ}$ período do curso de Alimentos, seguidos pelos alunos do $2^{\circ}$ período do curso de Informática (25\%) e, por último, está a turma do $1^{\circ}$ período do curso de Informática (6,25\%). Isso se explica pelo fato de que essa última turma conta com o menor número de alunos cadastrados na Biblioteca.

Além disso, a análise do quadro 2 demonstra que mais da metade dos empréstimos são de livros didáticos (53,12\%), acompanhados dos livros literários (25\%), técnicos/específicos $(14,06 \%)$ e, por fim, livros de entretenimento $(7,8 \%)$, que englobam assuntos gerais e que não se incluem nas demais categorias.

Esses dados refletem principalmente a utilização do empréstimo basicamente como fontes de estudo para as disciplinas ministradas em sala de aula, visto que os livros didáticos das disciplinas de língua portuguesa, matemática, geografia, história, biologia, química e física são os mais emprestados, assim como os livros de literatura (sobretudo brasileira), requeridos pelos programas das disciplinas. Os livros técnicos/específicos ficaram em penúltimo lugar possivelmente porque não abrangem ainda conteúdos dos períodos iniciais dos cursos e o baixo número de empréstimos dos livros de entretenimento sinalizam que os sujeitos não demonstram interesse em ler por prazer. 


\section{CONSIDERAÇÕES FINAIS}

Através do levantamento estatístico do cadastro de usuários e do empréstimo de livros aos alunos das turmas PROEJA, no turno noturno, constata-se que estes utilizam mais os livros obrigatórios, direcionados pelos professores e exigidos pelos programas das disciplinas. Provavelmente, neste material estão incluídos os conteúdos em que os usuários apresentam maiores dificuldades.

De acordo com os dados levantados, percebe-se que ainda é pequeno o número de alunos dessas turmas que são usuários da biblioteca. Para alterar esse quadro, recomenda-se a divulgação dos serviços desse setor junto aos professores, para que estes possam difundir a necessidade de utilização destes serviços aos alunos. Além disso, observa-se a necessidade de melhoria na quantidade e na qualidade do acervo, para atender às demandas dos usuários e tornar a biblioteca um ambiente mais atrativo para eles.

\section{REFERÊNCIAS}

BRASIL. Ministério da Educação. Secretaria de Educação Continuada, Alfabetização e Diversidade. Documento base nacional preparatório à VI CONFINTEA, 2008.

Disponível em <http://forumeja.org.br/files/docbrasil.pdf> Acesso 07 out. 2008.

BRASIL. Ministério da Educação. Programa de Integração da Educação Profissional com a Educação Básica na Modalidade de Educação de Jovens e Adultos - PROEJA: Educação Profissional Técnica de Nível Médio: Ensino Médio: Documento Base. Brasília: MEC, 2007.

BRASIL. Ministério da Educação. Secretaria de Educação Profissional e Tecnológica. Proeja. Disponível em :

$<$ http://portal.mec.gov.br/index.php?option=com_content\&view=article\&id=12288:progra ma-nacional-de-integracao-da-educacao-profissional-com-a-educacao-basica-namodalidade-de-educacao-de-jovens-e-adultos-proeja\&catid=259:proeja-\&Itemid=562> Acesso em : 05 fev. 2009.

BUENO, Silvana Beatriz. Fontes de informação utilizadas por professores do ensino fundamental. 2007. 120f. Dissertação (Mestrado em Ciência da Informação) - Programa de Pós-graduação em Ciência da Informação, Universidade Federal de Santa Catarina, Florianópolis, 2007. Disponível em: <http://www.cin.ufsc.br/pgcin/SilvanaBueno.pdf> Acesso em 06 maio 2009.

CENTRO FEDERAL DE EDUCAÇÃO TECNOLÓGICA DO RIO GRANDE DO NORTE - CEFET-RN. Unidade de Ensino Descentralizada de Currais Novos. Relatório de gestão da UNED Currais Novos 2007. Currais Novos, 2008. Disponível em: $<$ http://unedcn.dnsalias.org/downloads/relatorio_gestao_unedcn_2007.pdf> Acesso em: 07 maio 2009. 
DI PIERRO, Maria Clara; JÓIA, Orlando; RIBEIRO, Vera Masagão. Visões da educação de jovens e adultos no Brasil. Caderno Cedes, Campinas, ano 21, n.55, p. 58-77, nov. 2001.

FIGUEIREDO, Nice M. de Oliveira. Avaliação de coleções e estudo de usuários. Brasília: ABDF, 1979.

INSTITUTO FEDERAL DE EDUCAÇÃO, CIÊNCIA E TECNOLOGIA DO RIO GRANDE DO NORTE - IFRN. Histórico. Disponível em:

<http://www.ifrn.edu.br/institucional/historico> Acesso em: 07 maio 2009.

MOURA, Dante Henrique. A implantação do PROEJA no CEFET-RN: avanços e retrocessos. Disponível em:

$<$ http://www.cefetrn.br/unedzn/images/stories/ensino/14\%20a\%20implanta\%C7\%C3o\%20 do\%20proeja\%20no\%20cefet-rn\%20-\%20avan\%C7os\%20e\%20retrocessos.pdf > Acesso em: 05 fev. 2009.

PINHEIRO, Lena Vânia Ribeiro. Usuário $\leftrightarrow$ Informação: o contexto da ciência e da tecnologia. Rio de Janeiro: Livros técnicos e científicos, 1982.

RAMPAZZO, Lino. A pesquisa. In: Metodologia científica: para alunos dos cursos de graduação e pós-graduação. São Paulo: Edições Loyola, 2005. p. 49-60. 